2019-03-25

\title{
Walking with technology: understanding mobility-technology assemblages
}

Holton, Mark

http://hdl.handle.net/10026.1/13313

10.1080/17450101.2019.1580866

Mobilities

Taylor \& Francis (Routledge)

All content in PEARL is protected by copyright law. Author manuscripts are made available in accordance with publisher policies. Please cite only the published version using the details provided on the item record or document. In the absence of an open licence (e.g. Creative Commons), permissions for further reuse of content should be sought from the publisher or author. 


\section{Walking with technology: understanding mobility-technology assemblages}

Holton, Mark (2019) - School of Geography, Earth, and Environmental Sciences, Plymouth University

Accepted - 1 February 2019 (embargo until 1 August 2020)

Cite this article: Holton, M. (2019). Walking with technology: understanding mobilitytechnology assemblages, Mobilities. DOI: 10.1080/17450101.2019.1580866

\section{Abstract}

It is difficult to deny that technology - be it listening to music through headphones, engaging with smartphone apps or conversing through hands-free headsets - has become a ubiquitous part of everyday walking practices, influencing daily activities and shaping how these are operationalised. While digital technologies cannot replace conventional interactions with landscapes (e.g. the weather, clothing, street furniture, etc.), the intersections of people, places and technologies can converge in exciting and surprising ways to produce new forms of interrelating with(in) spaces. In this paper, I focus on the digital walking tour as a novel instrument through which to examine how mobility-technology assemblage assists with understanding how engagements with environments might produce various, contrasting assemblages of mobilities, bodies, affects, emotions and placemaking. I argue that participating within hybridised physical/digital spaces affects and is affected by different mobility practices. Through this paper, I propose that mobility-technology assemblage thinking provides new interventions into the ways in which people interact with technology, with each other and with(in) everyday spaces. Hence, while the persontechnology interface may be considered a largely individual experience, I posit that the amalgamation of people, places and technologies can, in fact, greatly influence how pedestrian experiences are assembled, transmitted, received and interpreted. 


\section{Keywords}

Assemblage, geography, mobility, walking, smartphone technology.

\section{Introduction}

Thirteen years have now passed since Sheller and Urry's (2006) New Mobilities Paradigm reshaped scholarly understandings of movement and stasis, not simply as relational binaries but as complex assemblages of systems, flows and networks that converge, overlap and collide with one another. One of the more persistent synergies that has developed from such mobilities-inflected thinking has been between mobility and technology - particularly in relation to how technologies might influence efficacy in our everyday lives (e.g. through the use of public and private transport and travel that facilitate mobilities (Grieco and Urry, 2011)). I argue though that this nexus needs further development and, through this paper, I propose a more critical examination of how mobility and technology operate in the context of assemblage thinking to help understand how complex flows and networks of people, places, technologies and mobilities affect everyday pedestrian activities.

Understanding assemblages in this way is important, particularly as technologyinflected walking has permeated our everyday lives, through the handheld and wearable technologies that monitor movements and the rhythms of the body, and connect people in different spatio-temporal contexts. I address this here by focusing upon how the human and the non-human, the embodied and the imagined, the material and the immaterial, the mobile and the static coalesce to co-produce different assemblages of everyday life. To achieve this I draw upon phenomenological approaches to delve into the subjective, embodied and lived experiences associated with walking (Casey, 2001; Kusenbach, 2003) and in doing 
so explore how such activities become enlivened through senses, imagination, perception and memory, among others (Relph, 1976). Indeed, Foucault $(1986,23)$ suggests that:

"[...] phenomenologists have taught us that we do not live in a homogeneous and empty space, but on the contrary in a space thoroughly imbued with quantities and perhaps thoroughly fantasmatic as well".

My thinking is therefore influenced by the approaches of Merleau-Ponty (1962) who positions the body as central to notions of perception, being situated between objective and subjective states of being. Merleau-Ponty (1968) argues that the body is borderless, adapting its reach and form according to social and environmental influences. Yet, he writes that the body does not belong exclusively to either the subject or the world, insofar as they are mutually relational, meaning the body is an intertwined state between the perceiver and the perceived. This contrasts with Heidegger's (1962) more interpretative stance that infers contextual understandings of how people, things, places, etc., are positioned in relation to others. These notions of the spaces of everyday life as permeated with vitality and effervescence provide an exciting point from which to interpret technology-assisted pedestrian mobilities in new ways, particularly in relation to the ways that technologies (specifically internetenabled smartphones) have changed our everyday walking practices through the various rhythms, tempos, energies and movements stimulated by them.

Walking practices (particularly urban walking) are situated within a rich canon of geographical work, with previous studies examining pedestrian activities in various contexts from running (Cook, Shaw and Simpson, 2016), active-transport (Millward, Spinney and Scott, 2013) and commuting (Bissell, 2018), to notions of sustainability 
(Middleton, 2011), sense-making (Degen and Rose, 2012) and orientation (Laurier, Brown and McGregor, 2016). To enliven this further I focus specifically upon the digital walking tour as a prevalent contemporary technology that encourages users to engage (differently) with the emotional-phenomenological dimensions of their external environment, specifically the embodied nature of 'experiencing' places from within (Bendiner-Viani, 2005). Crucially, I borrow from Tilley (2008) who argues that, through a phenomenological lens, walking operates as a conscious act. Certainly within my research, the use of a digital walking tour disturbs the 'realities' of walking, transforming it from a passive encounter into a set of space-time performances. The tour I focus on is entitled 'PlymTour', a digital walking tour smartphone application (hereafter referred to as 'app') of central Plymouth (UK) designed by a team of academic researchers to encourage university students to explore and learn about their term-time location. Through research carried out with users of the app, my colleagues and I critiqued how our participants negotiated what can be considered hybridised physical/digital spaces, and how such engagements might affect, and be affected by, different mobility practices. Understanding how engaging with technology in the 'outside' world might challenge everyday pedestrian activities is important and can explain a lot about how experiences of walking are assembled, transmitted, received and interpreted. I argue then that teasing apart these assemblages of people, places and technologies provides greater insight into how mobilities, bodies, affects, emotions and place-making contribute towards walking with technology practices.

In considering the geographies and mobilities involved here, I employ assemblage thinking as a critical lens through which to examine how digital mobile technologies like walking tour apps might usefully (re)produce different knowledges and 
understandings of mobility 'in place'. I follow the, now well-trodden, path of the mobilities turn in the social sciences that paved the way for new ways of considering the "complex, enduring, and predictable connections between peoples, objects, and technologies [that constitute networks and flows] across multiple and distant spaces and times" (Sheller and Urry, 2006:215-216). Mobility theorists have, of course, explored the influential dimensions of assemblage in mobility thinking (see notions of 'ethos' (Adey, 2012), 'vibration' (Bissell, 2010) and 'turbulence' (Cresswell and Martin (2012), among others), in order to tease out the various complementary and contrasting threads of mobility practices and bring these into sharper focus in new and exciting ways. Indeed, in relation to pedestrian activities, Middleton (2010:575) posits walking as:

"[...] positioned and understood as a socio-technical assemblage that enables specific attention to be drawn to the embodied, material and technological relations and their significance for engaging with everyday urban movements on foot".

Yet, while Middleton infers the body-place interactions within walking to be an arrangement of material and corporeal networks, I argue that body-technology interfaces provide alternative ways of considering these interactions that reflect our increasingly smartphone-driven lives.

\section{The body-technology interface}

The ubiquity of smartphones (Birenboim and Shoval, 2016) and other forms of wearable technology (Gilmore, 2015) have clearly pervaded many aspects of our everyday pedestrian mobilities. They encourage exploration, influence daily activities and shape how these are performed (Richardson and Wilken, 2009), providing 
opportunities to experience, interpret and connect to places in new ways. Yet, while digital technologies cannot replace conventional interactions with landscapes (e.g. the weather, clothing, the terrain, street furniture, etc.) (Laurier, Brown and McGregor, 2016), I argue that the intersections of people, places and technologies can converge in exciting and surprising ways to produce new forms of interacting with(in) spaces. Indeed, Kalin and Frith (2016:223) speculate that "people can use smartphones and location-based applications to engage deeply with physical space, particularly the intertwining of place and memory". As a contemporary materiality then, smartphones have enduring capacities to connect, comprising what van Doorn (2013) argues as endogenous and exogenous characteristics - endogenous in that they contain multiple software and hardware components that are uniquely configured to the owner and exogenous as they affect, connect and organise the owner's everyday life. Crucially, smartphone usage affords opportunities to move beyond simple dualistic interpretations of person-place connections and instead recognise these not as oppositional or complimentary forces but as messy arrangements of inter/intra related practices and performances (see Kinsley, 2014). An anecdotal example of this has been the installation of 'Lightlines' - neon strips embedded into pavements that change colour according to the traffic system - that are designed to react specifically to smartphone usage 'on the move' (BBC News, 2017). These responses to mobile smartphone use, while often derided and trivialised in the popular press, indicates quite how seriously planners and policymakers take their pervasive use. There is widespread recognition then that smartphones play an important role in how our daily lives operate, not just as influential tools or instruments but also as agential in our corporeal behaviours. Herman, Hadlaw and Swiss (2014:2) posit mobile technologies as assemblages of 
"multidimensional socio-technical practices" that converge through various materialities (e.g. devices, apps, etc.) and imaginaries (e.g. cultures, desires, etc.). I extend this by arguing for mobilities (e.g. movement, pausing, orienting, etc.) to be recognised as an additional, and important, dimension of these assemblages that influences how people, places and technologies are entwined in everyday life.

I propose that (re)engaging with the evolving assemblages involved in walking with technology can provide us with a timely intervention into recognising the forces involved in understanding how our interactions with technology, with our own bodies and with each other are performed with and within our everyday spaces.

Significantly, I argue that mobility-technology assemblage thinking moves the person-technology interface beyond being a largely individual experience. Instead, walking with technology presents an amalgamation of people, places, mobilities and technologies, both in physical and virtual realms, in ways that greatly influence how pedestrian experiences are transmitted, received and interpreted. To achieve this the rest of the paper is structured as following. After reviewing the extant literature and outlining the methods I divide the analysis into three sections. First, I examine how mobilities and technologies can coalesce to influence the energy and vitality of assemblages. Second, to extend notions of mobile assemblage as disaggregated and heterogeneous I question the transformative capabilities of various and contrasting ambiences, affects and atmospheres that can stimulate durability or capriciousness within assemblages. Third, I suggest that through the agentic and intra-active materialities associated with assemblages, mobilities need not be sinuous but can necessarily stutter, stumble and be iterative. In drawing these dimensions together, I argue that the sense of 'gritty vibrancy' associated with mobility-technology assemblage thinking helps interpret, more critically, the ways in 
which walking with technology challenges our experiences and interactions with the outside world.

\section{Conceptualising assemblage}

This paper draws upon conceptualisations of assemblage thinking that derive from Gilles Deleuze and Felix Guattari's seminal work 'A Thousand Plateaus' (1987), a manner of thinking that offers alternative and critical theorisations of social complexity. While assemblage is not a straightforward concept to define, Müller (2015:28) frames it "as a mode of ordering heterogeneous entities so that they work together for a certain time". This spatio-temporal dimension is crucial in understanding how assemblage thinking works. Assemblages can be considered cofunctioning (Deleuze and Parnet, 1987), in that they are non-linear, interruptible, open-ended and resistant to closure (Anderson et al., 2012). Yet as Müller and Schurr (2016) caution, assemblages can also be unpredictable, suggesting they are perhaps fleeting, fragile and susceptible to collapse. Notwithstanding this, assemblages function within Deleuze and Guattari's (1987) notion of the rhizome, operating as constellations that contain non-hierarchical entry and exit points. Hence, this 'fuzziness' means that assemblages are not discrete, singular entities but are constitutive of the assemblages of other components that, in turn, also contribute towards larger assemblages. They exist then as open systems that are subject to exterior influence (DeLanda, 2006; Law, 2004) that carry a certain dynamism that invites change (Waterton and Dittmer, 2014).

In providing a loose framework, Anderson and McFarlane (2011) posit assemblages to contain four essential characteristics. First, they are not fixed but can both cohere and disperse; second, assemblages are not entities in their own right but comprise 
distributions of agency among actants; third, assemblages are emergent rather than the result of a network and fourth, they are fragile, meaning attention must be given to the gaps that result from gatherings and dispersals. Müller (2015) recognises five further complimentary features, suggesting assemblages need to be relational, in that they link together with other components, and productive in generating new organisations, behaviours, etc.. As assemblages are non-hierarchical, they are heterogeneous; their fluid nature encourages them to de/re-territorialise through transformations; and they are desired, in that assemblages are energised through continuous flows and interactions. Assemblage thinking therefore allows for greater flexibility in recognising flows of human and non-human forms, less as (b)ordered, contained entities, but as melting and morphing constellations (Legg, 2011).

Moreover, assemblages are fundamentally processual in that different relational configurations may emerge or form. This means that the constituent parts of an assemblage operate autonomously and cannot be determined by relations or fully actualised. In the context of this paper, this has implications for how we might consider the socio-temporalities of interacting (with)in urban environments, particularly the materialities of public space. Farías and Bender (2010) argue that notions of the concretised city as a cohesive and bounded entity need critical reevaluation. Through assemblage thinking, they speculate that the urban is a complex constellation of hybridised, multiple and contrasting processes, practices and flows that, following Bruno Latour's (2004) definition of the actant, comprise imbricated human and non-human interactions. Moreover, Bennett (2010) infers that the material configuration of both human and non-human 'things' can disturb more linear ways of interpreting distributions and associations. For example, Edensor (2011:240) uses the repairing of a church to argue that "buildings are [...] assemblages of 
heterogeneous materials which (re)produce circulations of matter, labour and knowledge". In this sense, the building (and by association the block, the street, the city, etc.) become enduring assemblages that respond to and inform human and non-human agents. Henceforth, as Dewsbury (2011:150) succinctly states "[t]he assemblage is less about what it is [...], and more about what it can do, what it can affect and bring about".

\section{Assemblage thinking in a mobile world}

In advancing this work, I seek to interpret the role of mobility and technology in assemblage thinking - specifically how a variety of technological, environmental and corporeal dimensions might 'free up' mobility practices. Mobilities and assemblage have close epistemological relationships through the ways in which assemblages of flows, networks and processes have informed mobilities thinking (Hannam, Sheller and Urry, 2006). I build then upon work that seeks to explore this mobilitytechnology-assemblage nexus by teasing out more heterogeneous and disaggregated characteristics (Salter, 2013; Rink and Gamedze, 2016). My engagement with these ideas pursues a more critical understanding of the role of mobilities in producing, facilitating and transforming assemblages, while simultaneously being influenced by assemblage networks. To be clear, I follow Deleuze and Guttari's (1987) rules that assemblages are de-centred and nonhierarchical, hence I do not suggest that mobility is the central or 'key' proponent in the production of assemblage. I imply instead that mobility is simply an actant in itself, albeit an actant that plays a part in facilitating, shaping and being shaped by other relational dimensions within assemblages through various tempos, energies, movements, pauses and stops. My thinking is influenced by Anderson et al. (2012) 
who provide valuable insights into how mobilities may be implicated in assemblage thinking. They suggest that Deleuzian approaches posit assemblages to be sinuous and transformative, merging entities, but not containing them, and providing agency to these entities as the dynamics of assemblages change. This notion of agency is critical to understanding assemblages as being caught up in movement. Assemblages are neither fixed, static nor passive, implying degrees of agency between the constituent parts of an assemblage that drive it forward, slow it down, morph it into something new or cease it to exist at all. This is important because, as Anderson et al. (2012:181) argue, "different agents within assemblage[s] may possess different resources and capacities to act", again, inferring assemblages as emergent rather than as an end point but also deducing assemblages to exist in a state of flux. This links to Bennett's (2010) definition of 'vibrant matter' - the vitality and dynamism of human and non-human actants that influence efficacy - and more specifically 'thing power', "the curious ability of inanimate things to animate, to act, to produce effects dramatic and subtle" (6) through their own efficiency. I borrow then from Bennett's notions of 'thing power' to argue that the differing mobilities and immobilities of actants can contribute towards how assemblages are produced, reproduced, hybridised and even destroyed.

To incorporate mobility-technology perspectives into my assemblage thinking I consider work on media and communications that examine the ways in which mobile media has influenced contemporary culture and society (Ek, 2013). Here, interpretations of technology as (mobile) assemblage provide useful in-roads into understanding how assemblages of everyday life are produced and interpreted. Indeed, while research by de Souza e Silva (2006) and Lupton (2013) on the intersections between mobile technologies and space infer that smartphone usage 
hybridises space - blurring the accepted boundaries between geographical and virtual space (as well as bodies and technologies), there remains a rather persistent linearity in how interactions between bodies, environments, mobilities and technologies are performed. This adds further weight to why I consider assemblage an appropriate and dynamic lens through which to recognise the complex, messy, disordered and asymmetric connections associated with mobility-technology that coalesce and disaggregate over time. I extend this to reflect body-place-mobilitytechnology relationships, insofar as I advocate such technologies to be vital drivers for the creation and (re)definition of individual and group identities. In doing so, I question why mobility is absent from these discussions, particularly as mobilities are important constituent parts of these relational networks. Ek (2013) infers that, in relation to mobile technologies, mobility is an important dimension in making sense of contemporary society. Ek (ibid) borrows from Heidegger's (1962) notion of the hammer as a material object that oscillates from being 'present-at-hand' to 'ready-athand' to suggest that mobile technologies act as facilitators or mediators (Latour, 2002), providing opportunities to simultaneously challenge preconceptions of place and the sedimentation of knowledge of place. I draw upon this rendition of technology to consider how smartphones can be lifted beyond their materialities and provided agency within assemblages. In advancing Ek (2013), I argue through mobility-technology assemblage thinking that the assemblage, dis-assemblage and re-assemblage of convergent and divergent forms of mobility practices (e.g. walking with technology, with(in) locations, with interactions, etc.) encourages scholars to engage with new possibilities and challenges for understanding relationships and convergences with broader contemporary social and cultural issues.

\section{Methods}


Using mobile technologies, such as smartphones and apps, as research instruments is relatively recent in contemporary geographical research (DeLyser and Sui, 2013). They influence both self-directed research techniques (Neff and Nafus, 2016) and research with others (Hadfield-Hill and Zara, 2018) and are extolled for generating understandings of, among other things, how people relate to technology, how technology might affect relationships with places and how researchers might capture 'new' data in real time. This makes smartphone technologies well-placed to examine the practices and performances associated with mobility-technology assemblage. My narrative of mobility-technology assemblage was conceived from a project conducted in 2016/17 in which three researchers were tasked with designing 'PlymTour' - a self-guided walking tour of Plymouth (UK) intended as a tool for new undergraduate students to orient themselves in the city. The tour itself is housed within a free, institutionally managed app that is available to all University of Plymouth students and staff who have an institutional login. The tour is designed to encourage participants to engage with a range of familiar and unfamiliar sites within the city centre in order to understand more about the broader geographies that exist beyond the confines of the campus and adjacent student-centric spaces. Within the app, participants are provided access to written, visual and aural content about specific locations around the city (e.g. descriptions of locations, photographs, weblinks, quizzes, etc.) that they can access directly through their smartphones whilst exploring the terrain of the city centre. The tour comprises ten locations including important touristic, historical, social and commercial spaces.

After developing and testing the app ethical approval was granted for two of the researchers to conduct a study with first-year students recruited from the Geography department to examine more closely how participants might engage (or not) with the 
app's interface, the locations, the routes between them and the content. To achieve this, participant observation was used as an investigative method over other virtual or video ethnographies (see: Laurier, Brown and McGregor, 2016; Duggan, 2017). This was chosen to provide the participants a sense of self-directed freedom to move more fluidly within the app and the environment without interference from the researchers, but also partly as it was impermissible to film in some of the private locations along the tour. Observing these engagements 'at a distance', nevertheless retained place-based dimensions for the duration of the tours. To recruit participants, student groups undertaking a first-year module that contained a field-based assessment that closely aligned with the content and locations found within the tour were invited to take part in the research. Information sheets were provided to all students during their introductory practical sessions for the module that contained information about the tour, the research, and how to get involved. Four groups elected to be involved, comprising seventeen students in total. Crucially, these groups were self-selected, meaning group participants all knew each other, and the levels of knowledge about the technology and the locations varied among and between the groups (e.g. some participants were more familiar with Plymouth, while others were more adept with utilising location-based technologies). In preparation for each tour the participants were prompted to install/update the app and to ensure that their smartphones had a full battery ${ }^{1}$. Groups were instructed to meet at one of the two researchers' offices to be briefed on how to operate the app; the structure and intentions of the research; to complete consent forms; and to clarify any questions the participants might have. Aside from health and safety guidance it was decided at

\footnotetext{
${ }^{1}$ While the information sheets stated that smartphone ownership was not compulsory (those without could easily work with other group members), all involved owned their own smartphones and were able to download the app.
} 
this stage to not prejudice the tours by setting out specific rules or regulations. This facilitated a more 'natural' research environment that conveyed how the participants might interact with the app, but not direct too much how the researchers might want them to use it or behave whilst using it (Holton and Harmer, 2019). Crucially, as the analysis will demonstrate, this approach meant we could recognise the contents of the app as another component of the assemblage - as a tool that can both propel it, but that can also be moulded and manipulated by other dimensions of the assemblage. Each encounter took approximately 2.5-3 hours to complete and the groups were accompanied from a short distance as they walked around the city, observing their use of the app, their interactions with one another and with the environment. Our observations also involved dealing with feedback 'at a distance' (e.g. participants talking to researchers and/or the repeating or summarising of dialogue overheard during the encounters) which leant some interesting nuances to the data collection, making this an active, rather than passive, experience. All observations were voice recorded and later transcribed for analysis using Nvivo.

\section{A pause...discovery!}

In this section I reflect on how pausing as a process of mobility invites opportunities to reconfigure and refresh the rhythms of the assemblage. Moving this beyond simply being about a confluence of people (both groups and individuals), technologies, places, mobilities, etc. recognises how, through the rhythms and temporalities of everyday life (Lefebvre, 1991a) the rhizomatic qualities of assemblages may morph into something new. This analysis demonstrates how the energy and vitality produced through the confluence of technology and mobility can provide greater efficacy for those engaged with pedestrian practices. I summarise 
part of the walk with Group D - the point when the participants entered the Millbay area of Plymouth. This part of the city, situated in the district of East Stonehouse, was once a key commercial dockyard that was built by Brunel and provided an important gateway for passengers and freight into the South West of England and beyond. Over time, Millbay fell into decline and, by the mid-part of the $20^{\text {th }}$ Century, had become synonymous with prostitution and poverty. Millbay has, since the 1990s, received vast amounts of reinvestment and has redeveloped in line with many other global waterfront development projects. What was interesting here was the way in which the constellation of the rhizome - the temporal rhythms associated with being in this space (Lefebvre, 2004); the pauses, stops and fleeting movements; the season (spring) and time of day (early afternoon); the identities, background and wellbeing of the participants - simultaneously harmonised and clashed in unique spatio-temporal ways.

I concentrate on one male student's experience here. When we arrived we were over one hour into the tour and the group had begun to tire. This participant, along with most of the others, was observing a landscape he had never visited before, appraising the new apartment blocks, the expensive yachts, the pretty vistas of Cornwall in the distance, before shouting abruptly:

"I could see myself living here".

The rest of the group ignored him and had spread out, busily looking around, reading the content of the app and talking to one another. The male student was doing the same but then loudly exclaimed:

"Hey, did you know this used to be the red-light district?!" 
This drew laughter and jeers from the other participants who quickly huddled around the orator. He proceeded to read out excerpts of the app's content to his groupmates while furtively looking around - clearly surprised to have his first impressions of Millbay challenged.

While being in this location played an important role in facilitating how, where and when the participants inferred meaning in Millbay, the technology and their mobilities - particularly the tempo of the encounter - also contributed to how the environment was viewed and experienced, providing interesting new dimensions to the assemblage that questioned received knowledge and how it was interpreted. The technology - through the app and the content - certainly drove these participants' mobilities, slowing them down and encouraging them to pause, reflect and discuss their interpretations of what this location might mean and how this related to their readings of the space. What was crucial here though was the change in energy specifically the vitality and dynamism that this interruption injected into, what was swiftly becoming a passive and leading encounter.

Mobility played an important role here in teasing out the various dimensions of the assemblage. Alongside the technology, the assemblage was driven by the participants' own rhythms, desires and agendas as well as through the vibrancy of the materialities associated with the encounter (Bennett, 2010) and how this facilitated the flow of the assemblage. As Haggerty and Ericson (2000:607) infer "[f]lows exist prior to any particular assemblage, and are fixed temporarily and spatially by the assemblage". Hence, the mobilities associated with this part of the tour were assembled in particular ways through the use of the technology, the routes taken around the location, the stops and pauses made, the orienting of bodies in 
conjunction with features in the landscape, the interactions (or not) between group members, the propensity to move again. These were all assembled in unique and non-linear ways.

Spinoza (1996) writes on the conative body - the social sense of bodies affecting and being affected by other bodies - and this was demonstrated through the relationships and interconnections between person(s), place and technology that were co-produced (and reproduced) in and through Millbay in different ways. Assemblage, in this sense, can be considered somewhat unpredictable, always in a process of becoming through the multiple constituent components of the rhizome (Waterton and Dittmer, 2014). Deleuze and Guattari (1987) imply that the rhizome operates as fluid and non-hierarchical, varying its constituent parts and drawing in assemblages while casting off others. When relating this to how these mobilitytechnology assemblages operated in Millbay, it is clear to see that the technology in conjunction with affect and mobility encouraged novel dimensions of the assemblage to be drawn in. In extending this, it was evident through the production of new and unexpected knowledges that challenged the verisimilitude (the rendition of the world as it appears to the human eye) of the space as an inert landscape through which to passively passenger and instead unlocked the sinuous, porous capacities of the rhizome. This demonstrates how the materialities of the location itself - the palimpsest of what was present (the buildings, boats, residents, etc.) and what had existed in the past (the people and their daily performances and practices) - became enlivened through this mobility-technology assemblage. The buildings took on new characteristics, and the participants' imagined interpretations of the practices and performances associated with the darker histories of Millbay helped reinvigorate the assemblage, and the potential fissures and cracks that had started to appear through 
fatigue added a playful and cheeky note to what was first considered quite a sedate space.

\section{Assemblage transformed? The durable and the capricious}

This next section examines the coalescence of technology, experience and knowledge, alongside the affective ambiences associated with the landscape, and how these contribute towards a (re)shaping of assemblages - in this instance, through the changing dynamics of the participants' mobilities as they traversed the environment. In doing so, I develop notions of the heterogeneous, disaggregated assemblage (Salter, 2013) to expose the ability for assemblages to transform in divergent ways. While this infers unpredictability, this mode of thinking importantly reveals how mobilities and technologies can contribute towards the form, sustainability and reliability of assemblages in ways that provide potential for the central function of assemblages to be retained. I draw here on four encounters. The first two come from Groups B and C as they traversed the retail streets of the city centre, while the others come from Groups $A$ and $C$ at the points at which they reached the more dilapidated Union Street. These locations offer valuable contrasting insights that critique how technologies and mobilities can transform assemblages, and how durability and disorder can adapt assemblages that are perceptibly fragile, unstable and unpredictable (Müller and Schurr, 2016).

\section{The enduring assemblage}

I begin with the encounters with Groups B and C. Each group reached the city centre approximately 40-60 minutes into their walk, having already encountered two of the stops on the tour, and were heading towards the third - the Pannier Market situated in the West End of the main shopping area. The stretch of road they were 
following - New George Street - is pedestrianised and during both of the walks was busy with shoppers, street vendors and buskers providing a lively and warm feel:

“They're heading down New George Street and they seem very relaxed. The body language is quite laid back. The two girls are talking, the boy isn't really talking but he seems okay. [...] We've just stopped, we're now on New George Street outside Pavers Shoes where Argos used to be. Their phones are away and they seem to be just taking it in. New George Street is pretty busy today, there are a lot of people walking up the street so they are going slightly against the tide a little bit here. [...] Right, we're starting again. We're just at the top of the area where it's not pedestrianised. They're starting to look at the app but just the map at this point. They're trying to look and see on the maps where they're going but they seem pretty relaxed" (Group B).

"[...] in terms of the group dynamics, they're breaking up into smaller groups, pairs, and talking. They're not working individually on this, which is a good thing. I can hear them starting to compare some of their observations. [...] They still seem pretty relaxed. They're comfortably chatting about other things as well as the work. The group is quite spaced out. [...] They're playing around a little bit. I think they just seem to be fairly relaxed and happy to be in this location. It feels, I suppose, quite a sensible, safe space for them" (Group C).

To help explain these observations I incorporate notions of the mise-en-scène - the spatial organisation of visual (and other sensory) themes that produce different ways of seeing; interpretations of mood and ambience; and methods for understanding and negotiating place (Rose, 2013). While mise-en-scène is largely the reserve of 
the cinematic landscape, I draw upon Lukinbeal (2005) who argues that as the landscape is open to interpretation it functions as a cogent metaphor that is developed through individual readings of space. This revealed the constituent parts of the assemblage (the tempo of walking, the engagement with technology, the interactions between participants and with the environment) to operate in such ways as to facilitate comfort and stability in New George Street. Even though both days were grey and overcast the ambience of the space - the rhythm of the people milling around, the music performed by the street artists, the familiarity of transiting through a generic shopping area - encouraged the participants to become components in this mise-en-scène, spreading out into pairings and slowing the pace until it resembled 'bimbling' rather than purposeful walking. The conversations became more fluid and the participants laughed more, their phones were crucially, either put away, or if in their hands, were being waved around as they gesticulated, suggesting the technology had become a subconscious component of their bodily performances as opposed to being a self-conscious driver of these journeys.

Here we can visualise assemblage as an arrangement of material and immaterial things. Drawing on Bennett (2010), this city centre space, whilst implying inertia through each group's acquaintance with it is, in fact, infused with agency that promotes a more fluid sense of efficacy for the participants. This was witnessed through the collaborative and cooperative interactions between bodies, environment and technologies that generated these particular forces within the assemblage. Hence, while the walking tour as assemblage may seem somewhat coercive manipulating pedestrian activities to be performed in specific and determinant ways according to the content of an app - it is nonetheless, to follow Deleuze and Guttari 
(1987), desirable in that it produces flows, mobilities and interactions with entities that in turn produce different affects and ways on knowing or seeing the world.

\section{Alarm and the capricious assemblage}

This next example comes from the walks with Groups A and C and provides an account of how the assemblage can be destabilised, fractured and potentially ruined by constituent and extraneous actants. I focus here on the points at which each of the groups had reached Union Street, another location in East Stonehouse that was once famous for world-renowned theatres that hosted the likes of Houdini and Laurel and Hardy but now has a foreboding sense of dereliction and has become infamous among successive student cohorts as a self-styled no-go area. Group C approached Union Street from the city centre in a way redolent of the earlier examples, chatting and laughing, while Group A were tense as they had previously been lost and argued. For both groups, their walking pace had been slow and in each instance the groups had split into pairings with a few metres distance in-between them. Once they reached Union Street though, everything changed:

"The body language and pace has changed a lot. One of the girls has got a pen in her hand and she keeps clicking it on and off. She's using it, holding it, quite tightly in her fist. [...] Another is clutching her folder quite close to her chest. She looks really uptight. [...] They've really pulled in tight but they're not all looking at one phone, they're looking at their own phones [...] they are looking at their phones while walking and not stopping. [...] So, they moved through [Union Street] in the quickest possible route, heads down, moving forward, no talking" (Group A). 
"Okay, so two of the girls [are] walking in the middle of the group at the moment, one has just asked the other, 'So what feelings are you feeling?' and the other one has said, 'I'm not really sure. I feel not very secure. I feel very vulnerable right now'. We are just coming up towards the roundabout [that leads onto Union Street]. There's nothing particularly that I would have thought would make someone feel that at this point but nonetheless, that's their interpretation of it at this stage. [...] One of the boys is questioning whether or not they should take some photos, discussing about how depressing it is that the New Palace Theatre has shut down and it's quite derelict. Two guys have just walked past us and were taking the mickey [sic]. I don't think the students noticed" (Group C).

These accounts reveal an important metamorphosis in how the characteristics of the assemblages (the energy and speed of walking, the ambience and engagement with the location, the body language and stowing away of phones) were operationalised. In both instances, the group dynamics transformed quickly from almost somnambulism to more emotionally and affectively charged interactions with Union Street that influenced significantly how mobilities were practiced and performed. For Group A this meant quietening down and speeding up, while for Group C, this was visibly and verbally expressed as vulnerability. Although the change in atmosphere appeared to upset the assemblage in both instances - closing the groups down, changing the moods of the encounters, reconfiguring how the participants related to their technologies - the discomfort experienced by some of the actants also sought to revitalise it. As Bennett (2010:23-24) argues: "[a]ssemblages are living, throbbing confederations that are able to function despite the persistent presence of energies that confound them from within". This chimes well with Cresswell and Martin's 
(2012:516) consideration of the chaos, disorder and unpredictability associated with turbulent mobilities that contrast "with the smooth operation of infrastructural mobilities that are supposed to remain silent and invisible". As Cresswell and Martin (ibid) imply, these types of movement exist as mobilities that defy expectation, or put another way, as mobilities that bring (dis)order into being. This is important, and in relation to the mobility-technology assemblage, the convergence and divergence of human and non-human actants are clear to see. Some smooth the assemblage while others agitate it, meaning power is not centrally governed but is contingent upon the formulations of the network at any given time.

As with the earlier example of Millbay I consider then how some of the affective dimensions associated with Union Street contributed towards how these assemblages were mobilised. I borrow from Anderson's (2009:80) interpretation of affective atmospheres as always emerging and transforming: "[...] becoming part of feelings and emotions that may themselves become elements within other atmospheres". In these Union Street examples, it was evident that the ambient dimensions of the space contributed towards the shaping of the assemblage through the paradoxical senses of foreboding, gloom, concern and curiosity that emanated from the group as they traversed this street. Yet, crucially, in relation to Jensen, Sheller and Wind's (2015) notions of affective ambiences, this was a 'morethan-individual' experience that produced a range of contrasting desires among many of the participants to vacate. This is important as desire acts as an inherent force within assemblage thinking (Haggerty and Ericson, 2000). Within this research, it was clear that these affective dimensions were instrumental in the desire, for many, to leave Union Street, energising the assemblage not through the excitement 
of having preconceived ideas playfully challenged as in the Millbay example, but to utilise mobility as a mechanism through which to escape.

In both instances, the participants drew together more tightly, they spoke less, held stern faces and looked furtively and worriedly around the landscape. Their phones spent longer in their pockets and interactions here were deliberate and sharp, only revealing their phones to check notes quickly or to take photographs. In line then with Waterton and Dittmer's (2014) research on museum assemblages, the participants' mobilities were affected by the atmosphere and ambience of Union Street - the sensorial dimensions that they associated with dereliction and decay. Yet rather than simply reacting to this, they embodied it through their corporeal rhythms, activating new elements of the assemblage that threatened to change its dimensions. Merleau-Ponty (1968:139), writes that while "the seer is caught up in what he [sic] sees, it is still himself [sic] he [sic] sees", suggesting the landscape itself becomes a reflection of the viewer's state of being (Lund, 2012). Yet, while Merleau-Ponty is concerned with a presumably 'typical' sense of embodiment, the ways-of-being in the world experienced here suggest something else. Taking a postphenomenological approach that suggests knowing and being-in-the-world to be translated differently by individuals (Richardson and Wilken, 2009) signifies a more complex palimpsest of experiences, histories and perceptions that generate unique understandings of, and relationships with, place. This is important in encouraging thinking that considers mobility-technology assemblages not simply as a set of relational processes. Instead this provides an understanding of how the spaces, and interactions with(in) the environment, and the knowledges, affects, emotions and mobilities produced (and practiced) through these interactions are formed through, 
what Lefebvre (1991b) considers as the confluence of physical, mental and social dimensions.

To draw these examples together I focus on Deleuze and Guttari's (1987) notion of the body as assemblage as a helpful prism through which to explain how and why the confluence of bodies, technologies, affects and environments produced quite specific and contrasting mobilities among the participants of each group. Currier (2003) infers Deleuze and Guttari's interpretations of bodily flows as:

"[...] collections of disparate flows, materials, impulses, intensities and practices, which congeal under particular and specific conditions, in complex relations with the flows and intensities of surrounding objects, to produce transitory but functional assemblages" (326).

To advance this I draw on Foucault's (1986) reading of 'other spaces' to interpret the mobilities associated with these assemblages, not as linear or processual (or even as necessarily relational to one another), but as part of a much larger web of social activity through which everyday urban sociability occurs. Indeed, Foucault's reading of space as both internally and externally perceived and experienced ponders just the types of juxtapositions, contradictions, relationships and correspondences that were experienced by these participants on their journeys.

I propose the biological process of 'instar' - the metamorphosis or moulting of one form into another - as a novel approach to thinking about how the direction(s), ambience(s) and dimension(s) of mobility-technology assemblages can be transformed. The butterfly that emerges transformed from a chrysalis will always be, fundamentally, a caterpillar. Thus so, under a variety of conditions, assemblages will 
morph in their form - shifting between durability and capriciousness - but will ultimately retain their central function through the desire for completion.

\section{Getting lost - intra-activity and agency}

This final example examines how the mobility-technology assemblage is affected by intra-activity and agency. This is important in acknowledging that while technologies can be persuasive in encouraging assemblages associated with walking to transform or endure, the mobilities associated with this can also produce conditions of (dis)order that imbue the rhizome with the necessary vibrancy to stimulate activity. Anderson et al. (2012) infer the autonomous agency of actants (both human and non-human) in affecting the nature of the assemblage, and it is this intra-activity the relationship between the constituent parts of the assemblage and the constellation of the assemblage at any given time - that I focus on here. In extending this, I argue that intra-activity and agency have implications for how assemblages are mobilised - particularly in the context of a group, whereby collaboration and resistance can change the energy within an assemblage, thus altering its dimensions and vitality (Bennett, 2010).

This example comes from the encounter with Group A at a midway point in their tour in which they were travelling between stops. The guidance on the app instructed the group to 'cross over the road into East Stonehouse' but with various routes afforded to them (a pedestrian crossing, underpass and overpass), they appeared confused and hesitant in how to proceed:

"They're deciding about where they're going to go next. They're looking towards Frankfort Gate and they're deciding on whether or not to start to head down towards East Stonehouse. I don't think they're particularly sure about 
how to do it. They're reading the instructions in the app, which is quite crucial. [...] They're just heading up onto the overpass that heads over the road towards Toys-R-Us. They're walking quite slowly, I'm not sure they feel hugely sure about what they're doing. I certainly get the feeling that this is not a place that they come to regularly, or maybe have ever come to. [...] One of them has the app out - they're stopping and starting. They still look quite nervous. [...] They're consulting the app and looking around" (Group A).

Once they had corrected themselves and continued walking over the bridge things improved, however, this gave way to a sense of unease among the participants over what to do next and some tensions arose between group members:

"One of them has got her phone out and is starting to look at the app. [...] They just seem a bit confused, they're questioning where they're supposed to be at the moment. One of them is trying to take the lead, and one of the other one's is saying, 'Are you sure? Are you sure?'. It will be interesting to see how they get around this. One of the students has just said, 'Can't we just walk and see where we're going?'. Okay, so we're turning right. It looks like we're going to cross over, which is not right. If we cross over we miss out East Stonehouse and we'll end up going down towards Union Street. One of the girls is now pointing towards East Stonehouse. [...] They're tracing the map. I think they're trying to decide whether or not to go down Western Approach towards Union Street, which they are. So we're not going to go through East Stonehouse now, we're going to go straight ahead. [...] Right, [they have realised] they've made this mistake. Okay, they've now rectified it. We're working backwards now, so we're going back. They've looked at the app and 
decided that where they were going wasn't right so they've rectified it. Instead of just wandering aimlessly they've actually stopped and thought about this to make it work out" (Group A).

In considering intra-activity as an important dimension of mobility-technology assemblage I draw on Latour's (1992:233) explanation of the "distribution of competences between humans and nonhumans" to infer the relationship between knowledge, trust (in both the technology and the group) and agency in aiding the stability of the encounter and sustaining the mobilities associated with the mobilitytechnology assemblage. In this sense, the mobilities produced here appear similar to the first example from Millbay - of pausing, recalibrating and moving on - yet the excerpts above attest to something quite different - of trial and error, experimentation and iteration, but also of tension. Importantly, I identity mobilitytechnology assemblages as not always emerging, or sinuous, flowing processes. Instead, they can stutter, stumble and work iteratively (i.e. through mistakes). This was evident in how the group interacted differently with the technology and with one another once they realised they were lost, with some taking charge and using the maps within the app to locate them while others became concerned, annoyed or passively acquiesced while problems were solved around them.

Taylor (2009:336), in discussing the various on-screen assemblages of players involved in multiplayer computer games, argues that "[...] complex set[s] of relationships [exist] between not only the player and their software, but the collective use of software and the production of group practices". While Taylor does not explicitly specify agency as an important dimension of group practices, I infer similar connections within my participants' encounters whereby the assemblage is produced 
and transformed through agential performances and the subsequent impacts upon the group's momentum in terms of slowing them down, confusing them, generating tension and disquiet and then propelling them forward again. Connolly (2005, c.f. Anderson et al., 2012) infers 'immanent causality' as a method for understanding the unpredictability and instability of assemblage when faced with unease or ambiguity. In my research, the novelty and surprise that comprised these non-linear systems affected, and were affected by, the mobilities associated with the assemblage (Bennett, 2010; Anderson et al., 2012). Notwithstanding this, in relation to mobility-technology assemblage thinking, the smartphone (and associatively the app contained within the device) operates as an 'assemblage convertor' (Deleuze and Guttari, 1987:378), a deterritorialised component that is "neither an archaism nor transitional or part-object". The app as a component of mobility-technology assemblage does not deter the everyday practices of walking through the city (the app constitutes an event, rather than a method for walking itself), nor does it affect how this is actioned or the outcome of doing it (the participants could indeed, just turn it off and still continue walking), yet, as Bennett (2010) acknowledges, it as a 'thing' is persuasive, in that it acts, when required, as a force that encourages the assemblage to either transform or endure.

\section{Conclusion}

"As we step of the house on a fine evening between four and six, we shed the self our friends know us by and become part of that vast republican army of anonymous trampers, whose society is so agreeable after the solitude of one's room. [...] Into each of these lives one could penetrate a little way, far enough to give one the illusion that one is not tethered to a single mind, but 
can put on briefly for a few minutes the bodies and minds of others" (Woolf, 1930, c.f. Solnit, 2006:16).

I choose to conclude this analysis with a quote from Virginia Woolf's Street Haunting: a London Adventure that, I believe, evocatively captures the transformative capacities of walking as mobility-technology assemblage. Woolf's essay is ostensibly concerned with identity and difference - and, of course, does not involve smartphone technologies - yet, I see this passage as skilfully apprehending both the passivity of the homogenous 'army' that processes through space, and the Self as a component in a much larger constellation of bodies and minds that exists in contemporary (and entangled) virtual/geographical experiences of everyday space. What links Woolf's extract to my mobility-technology assemblage thinking is the sinuous, fleeting and unpredictable nature of walking with technology. Woolf uses terminology such as 'tramping' and being 'tethered' that, for me, conjures notions of mobilities that either congeal or free the assemblage, of being synchronised with the masses while also having opportunities to create unique personal connections with people and the environment. I extrapolate these contemplations on the complexity of walking to my own analysis of walking with technology and specifically how this relates to mobilitytechnology assemblage thinking. Through my observations of the digital walking tour as mobility-technology assemblage I view these processes as more than simply a confluence of walking, technologies, mobilities, people, environments and affects but as operating as an allegory that encapsulates Deleuze and Guttari's (1987) directives of assemblage as simultaneously everything and nothing.

Through my analysis of mobility-technology assemblage using the digital walking tour, I have explored the contrasting roles of mobilities and technologies in 
facilitating, transforming and destabilising the rhizomatic constellations associated with assemblages. This has revealed three key contributions: first, that mobilities and technologies influence the energy and vitality of assemblages, producing flows and interactions that can provide greater efficacy for those engaged with pedestrian practices. Second, while mobilities and technologies can transform the characteristics of assemblages - influencing their form, sustainability and reliability my research demonstrates that these dimensions also facilitate assemblages by ensuring they retain their central function through the desire for completion. Finally, through notions of being lost I argue that mobility-technology assemblages need not always be sinuous but can also stutter, stumble and be iterative. Here, I suggest that while technologies can be persuasive in encouraging the assemblages associated with walking to transform or endure, the mobilities associated with this produce conditions of (dis)order that imbue the rhizome with the necessary vibrancy to stimulate activity.

In moving forward then, my interpretation of mobility-technology assemblage thinking emphasises the important transformative characteristics of assemblages that provide both durability and capriciousness. In drawing upon Cresswell and Martin (2012), I argue that the convergence and divergence of human and non-human actants simultaneously smooth and agitate assemblages, meaning power is not centrally governed but is contingent upon the formulations of the network at any given time. This extends more 'typical' considerations of the embodied sense of pedestrian activities (Merleau-Ponty, 1968) to signify a more complex palimpsest of experiences, histories, senses and perceptions that generate unique understandings of, and relationships with, place (Richardson and Wilkin, 2009). I, therefore, advocate more critical deliberations of mobility and technology practices that move 
beyond simply viewing assemblage as a set of relational processes. In doing so, I argue that mobility-technology assemblages provide greater understandings of how spaces and interactions within environments, as well as the knowledges, affects, emotions and mobilities produced (and practiced) through these interactions are (trans)formed. As Foucault's (1986) reading of 'other spaces' attests, the mobilities associated with such mobility-technology assemblages exist as part of a much larger web of social activity through which everyday urban sociability occurs. Hence, it is just this messy constellation of juxtapositions, contradictions, relationships and correspondences that were experienced by my participants as they traversed the urban landscape that makes mobility-technology assemblages curious. Borrowing from Bissell's (2010) evocative interpretations of the embodied 'shuddering and shaking' of railway journeys, I argue then that the affective and embodied mobilities produced through the performances and practices of walking with technology add their own gritty vibrancy that necessarily reawakens and facilitates constantly emerging mobility-technology assemblages.

\section{Acknowledgements}

Thank you to my co-investigators - Dr Nichola Harmer and Dr Rebecca Vickerstaff and to Dr David Tyfield and the three anonymous reviewers for their encouraging feedback. A version of this paper was given at the 'Beyond the Pedestrian' conference, convened by Dr Morag Rose, at the University of Liverpool in 2018.

\section{Funding}

This research was funded by a University of Plymouth 'Pedagogic Research and Teaching Innovation' Grant - Award Number: GH102007-121. 


\section{References}

Adey, P. 2012. "How to engage? Assemblage as Ethos/ethos as Assemblage." Dialogues in Human Geography 2(2): 198-201.

Anderson, B. 2009. "Affective Atmospheres." Emotion, Space and Society 2(2): 7781.

Anderson, B., M. Kearnes, C. McFarlane and D. Swanton. 2012. “On Assemblages and Geography." Dialogues in Human Geography 2(2): 171-189.

Anderson, B. and C. McFarlane. 2011. "Assemblage and Geography." Area 43(2): 124-127.

BBC News. 2017. "Crossing lights for smartphone zombies."

https://www.bbc.co.uk/news/av/technology-38992655/crossing-lights-forsmartphone-zombies

Birenboim, A., and N. Shoval. 2016. "Mobility Research in the Age of the Smartphone." Annals of the American Association of Geographers 106(2): 283-291.

Bendiner-Viani, G. 2005. "Walking, Emotion, and Dwelling: Guided Tours in Prospect Heights, Brooklyn." Space and Culture 8(4): 459-471.

Bennett, J. 2010. “Vibrant Matter: A Political Ecology of Things.” Durham: Duke University Press.

Bissell, D. 2010. "Vibrating Materialities: Mobility-body-technology Relations." Area 42(4): 479-486. 
Bissell, D. 2018. "Transit Life: How Commuting is Transforming Our Cities." Cambridge: MIT Press.

Casey, E.S. 2001. "Between Geography and Philosophy: What Does it Mean to be in the Place-world?" Annals of the Association of American Geographers 91(4), 683693.

Cresswell, T., and C. Martin. 2012. "On Turbulence: Entanglements of Disorder and Order on a Devon Beach." Tijdschrift voor economische en sociale geografie 103(5): 516-529.

Cook, S., J. Shaw, and P. Simpson. 2016. “Jography: Exploring Meanings, Experiences and Spatialities of Recreational Road-Running." Mobilities 11(5): 744769.

Currier, D. 2003. "Feminist Technological Futures: Deleuze and Body/Technology Assemblages." Feminist Theory 4(3): 321-338.

de Souza e Silva, A. 2006. "From Cyber to Hybrid: Mobile Technologies as Interfaces of Hybrid Spaces." Space and culture 9(3): 261-278.

Degen, M.M., and G. Rose. 2012. "The Sensory Experiencing of Urban Design: the Role of Walking and Perceptual Memory." Urban Studies 49(15): 3271-3287.

DeLanda, M. 2006. "A New Philosophy of Society: Assemblage Theory and Social Complexity." London: Continuum.

Deleuze, G., and F. Guattari. 1987. "A Thousand Plateaus: Capitalism and Schizophrenia." London: Bloomsbury Publishing. 
Deleuze, G., and C. Parnet. 1987. “Dialogues.” London: Athlone.

DeLyser, D., and D. Sui. 2013. "Crossing the Qualitative-Quantitative Divide II: Inventive Approaches to Big Data, Mobile Methods, and Rhythmanalysis." Progress in Human Geography 37(2): 293-305

Dewsbury, J.D. 2011. "The Deleuze-Guattarian Assemblage: Plastic Habits." Area 43(2): 148-153.

Duggan, M. 2017. "Questioning "Digital Ethnography" In an Era of Ubiquitous Computing." Geography Compass 11(5): DOI:10.1111/gec3.12313.

Edensor, T. 2011. "Entangled Agencies, Material Networks and Repair in a Building Assemblage: the Mutable Stone of St Ann's Church, Manchester." Transactions of the Institute of British Geographers 36(2): 238-252.

Ek, R. 2013. "Topologies of Human-mobile Assemblages." In Mobile Technology and Place, edited by R. Wilken, R. Goggin 51-66. London: Routledge.

Farías, I., and T. Bender. 2012. "Urban Assemblages: How Actor-Network Theory Changes Urban Studies." London: Routledge.

Foucault, M. 1986. "Of Other Spaces." Diacritics 16(1): 22-27.

Gilmore, J.N. 2016. "Everywear: the Quantified Self and Wearable Fitness Technologies." New Media \& Society 18(11): 2524-2539.

Grieco, M., and J. Urry. 2016. "Mobilities: New Perspectives on Transport and Society." London: Routledge. 
Hadfield-Hill, S., and C. Zara. 2018. "Being participatory through the use of appbased research tools." In Being Participatory: Researching with Children and Young People, edited by I. Coyne B. Carter 147-169. Switzerland: Springer.

Haggerty, K.D., and R.V. Ericson. 2000. "The Surveillant Assemblage." The British journal of sociology 51(4): 605-622.

Hannam, K., M. Sheller, and J. Urry. 2006. "Mobilities, Immobilities and Moorings." Mobilities 1(1): 1-22.

Heidegger, M. 1962. "Being and time." Oxford: Blackwell.

Herman, A., J. Hadlaw, and T. Swiss. 2014. "Theories of the Mobile Internet: Materialities and Imaginaries." London: Routledge.

Holton, M. and N. Harmer. 2019. "'You Don't Want to Peer Over People's Shoulders, it Feels Too Rude!': The Moral Geographies of Using Participants' Personal Smartphones in Research." Area 51(1): 134-141.

Jensen, O.B., M. Sheller, and S. Wind. 2015. "Together and Apart: Affective Ambiences and Negotiation in Families' Everyday Life and Mobility." Mobilities 10(3): 363-382.

Kalin, J., and J. Frith. 2016. "Wearing the City: Memory P(a)laces, Smartphones, and the Rhetorical Invention of Embodied Space." Rhetoric Society Quarterly 46(3): 222235.

Kinsley, S. 2014. "The Matter of 'Virtual' Geographies." Progress in Human Geography 38(3): 364-384. 
Kusenbach, M. 2003. "Street Phenomenology: the Go-Along as Ethnographic Research Tool." Ethnography 4(3): 455-485.

Latour, B. 1992. "Where are the Missing Masses? The Sociology of a Few Mundane Artefacts." In Shaping technology/building society, edited by W. E. Bijker J. Law 205224. Cambridge: MIT Press.

Latour, B., 2002. "Morality and Technology: the End of the Means." Theory, Culture and Society 19(5-6): 247-260.

Latour, B. 2004. "Politics of Nature." Cambridge: Harvard University Press.

Laurier, E., B. Brown, and M. McGregor. 2016. "Mediated Pedestrian Mobility:

Walking and the Map App. Mobilities 11(1): 117-134.

Law, J. 2004. "After Method: Mess in Social Science Research." London: Routledge.

Lefebvre, H. 1991a. "Critique of Everyday Life: Foundations for a Sociology of the Everyday." London: Verso.

Lefebvre, H. 1991b. "The Production of Space." Oxford: Blackwell.

Lefebvre, H. 2004. "Rhythmanalysis: Space, Time and Everyday Life." London: Bloomsbury.

Legg, S. 2011. "Assemblage/apparatus: Using Deleuze and Foucault." Area 43(2): 128-133.

Lukinbeal, C. 2005. "Cinematic Landscapes." Journal of Cultural Geography 23(1): $3-22$. 
Lund, K. 2012. "Landscapes and Narratives: Compositions and the Walking Body." Landscape Research 37(2): 225-237.

Lupton, D. 2013. “The Digital Cyborg Assemblage: Haraway's Cyborg Theory and the New Digital Health Technologies." In The handbook of social theory for the sociology of health and medicine, edited by F. Collyer 567-581. Houndmills: Palgrave Macmillan.

Merleau-Ponty, M. 1962. "Phenomenology of Perception." London: Routledge.

Merleau-Ponty, M. 1968. "The Visible and the Invisible: Followed by Working Notes." Evanston: Northwestern University Press.

Middleton, J. 2010. "Sense and the City: Exploring the Embodied Geographies of Urban Walking." Social \& Cultural Geography 11(6): 575-596.

Middleton, J. 2011. "Walking in the City: the Geographies of Everyday Pedestrian Practices." Geography Compass 5(2): 90-105.

Millward, H., J. Spinney, and D. Scott. 2013. "Active-transport Walking Behavior: Destinations, Durations, Distances." Journal of Transport Geography 28: 101-110.

Müller, M. 2015. "Assemblages and Actor-Networks: Rethinking Socio-Material Power, Politics and Space." Geography Compass 9(1): 27-41.

Müller, M., and C. Schurr. 2016. "Assemblage Thinking and Actor-Network Theory: Conjunctions, Disjunctions, Cross-fertilisations." Transactions of the Institute of British Geographers 41(3): 217-229.

Neff, G., and D. Nafus. 2016. "Self-Tracking." Cambridge: MIT Press. 
Relph, E. 1976. “Place and Placelessness." London: Pion

Rink, B.M., and A.S. Gamedze. 2016. "Mobility and the City Improvement District: Frictions in the Human-capital Mobile Assemblage." Mobilities 11(5): 643-661.

Richardson, I., and R. Wilken. 2009. "Haptic Vision, Footwork, Place-making: a Peripatetic Phenomenology of the Mobile Phone Pedestrian." Second Nature: International journal of creative media 1(2): 22-41.

Rose, G. 2012. "Visual Methodologies: an Introduction to Researching With Visual Material." (3rd ed). London: SAGE.

Salter, M.B. 2013. "To Make Move and Let Stop: Mobility and the Assemblage of Circulation." Mobilities 8(1): 7-19.

Sheller, M., and J. Urry. 2006. "The New Mobilities Paradigm." Environment and planning A 38(2): 207-226.

Solnit, R. 2006. "A Field Guide to Getting Lost." Edinburgh: Canongate Books.

Spinoza, B. 1996. "Ethics." London: Penguin

Taylor, T.L. 2009. "The Assemblage of Play. Games and Culture 4(4): 331-339.

Tilley, C. 2008. "Body and Image: Explorations in Landscape Phenomenology 2." Walnut Creek: Left Coast Press.

van Doorn, N. 2013. "Assembling the Affective Field: How Smartphone Technology Impacts Ethnographic Research Practice." Qualitative Inquiry 19(5) 385-396. 
Waterton, E., and J. Dittmer. 2014. "The Museum as Assemblage: Bringing Forth Affect at the Australian War Memorial." Museum Management and Curatorship 29(2): 122-139. 